\title{
Responses of the predatory species, Coccinella undecimpunctata L. (Coleoptera: Coccinellidae), to the volatiles from its prey, Aphis craccivora Koch. and Vicia faba plant
}

\author{
Hany Ahmed Fouad(D)
}

\begin{abstract}
Background: Plants after infestation emit specific volatiles, which can influence foraging behavior of insect predators of herbivores. This work aimed to evaluate the responses of the predatory species, Coccinella undecimpunctata L. (Coleoptera: Coccinellidae), adults to volatiles emitted from its cowpea aphid prey, Aphis craccivora (Koch.), and from Vicia faba plant to improve the efficiency of searching for its prey. An olfactometer bioassay was used for this investigation.

Results: The results revealed that both male and female of $C$. undecimpunctata significantly used olfactory cues from infested plant + aphids, but the mated females exhibited a complete response (47.50\%). The mated male was attracted to aphids (30.0\%) more than other tested predatory types, indicating the capacity to exploit volatiles induced by aphids.

Conclusions: The results supported that $C$. undecimpunctata adult uses plant volatiles induced by A. craccivora infestation, which might act as reliable indicators to find its prey.
\end{abstract}

Keywords: Coccinella undecimpunctata, Aphis craccivora, Vicia faba, Olfactometer, Free choice, Semiochemicals

\section{Background}

The faba bean plant (Vicia faba L.) is an essential crop in several regions of worldwide, including Egypt. The cowpea aphid, Aphis craccivora (Koch.) (Homoptera: Aphididae), is one of the serious aphids' species of this crop (Salman et al. 2007). Aphid's population can become very abundant over time, and space damaging the plants directly by sucking sap and indirectly through transmitting viruses (Dedryver et al. 2010). Beetles of the family Coccinellidae (Coleoptera), including Coccinella undecimpunctataL., are considered potential predators of aphids, including A. craccivora (Jabbar et al. 2020). Plants produce several secondary volatile compounds that are important in insect-plant

Correspondence: haafouad@yahoo.com

Plant Protection Department, Faculty of Agriculture, Sohag University, Sohag, Egypt

\section{Springer Open}

interaction. These volatiles can be attractant for the insects for feeding, mating, and oviposition (Norkute et al. 2020). Recently, several investigators found that many plants attacked by herbivore insects indirectly defend themselves by emitting volatiles, which adaptively increases natural enemies' efficiency by reducing searching time and increasing attack rates on their hosts (Ninkovic et al. 2001). However, very little attention has been dedicated to the role of semiochemicals emitted by legume plants and aphids on natural enemies' searching behavior, especially the predators. Therefore, this work aimed to evaluate the role of volatiles emitted from A. craccivora aphid and $V$. faba plant in increasing the efficiency of C. undecimpunctata adults on searching capacity.

(c) The Author(s). 2021 Open Access This article is licensed under a Creative Commons Attribution 4.0 International License, which permits use, sharing, adaptation, distribution and reproduction in any medium or format, as long as you give appropriate credit to the original author(s) and the source, provide a link to the Creative Commons licence, and indicate if changes were made. The images or other third party material in this article are included in the article's Creative Commons licence, unless indicated otherwise in a credit line to the material. If material is not included in the article's Creative Commons licence and your intended use is not permitted by statutory regulation or exceeds the permitted use, you will need to obtain permission directly from the copyright holder. To view a copy of this licence, visit http://creativecommons.org/licenses/by/4.0/. 


\section{Methods}

\section{Insect colonies}

The aphid A. craccivora colonies were collected from the Experimental Farm, Faculty of Agriculture. Then, they were maintained in a growth chamber at $(25 \pm 2$ ${ }^{\circ} \mathrm{C}, 65 \pm 5 \% \mathrm{RH}$, and a 16-h photoperiod) on bean plants grown in 15-cm-diameter plastic pots, using a fritted clay and peat moss medium. When plant stems "reached" $8 \mathrm{~mm}$ diameter, they were placed into doublewalled delicate nylon-mesh cages $(40 \times 34 \times 50 \mathrm{~cm})$, and aphids were released and allowed to settle down on the plants and multiply. Plants that became severely necrotic from aphid feeding were replaced with fresh ones. The ladybeetle, C. undecimpunctata, was collected from the wheat plants located at the same farm, maintained in a growth chamber $\left(25 \pm 2{ }^{\circ} \mathrm{C}, 65 \pm 5 \% \mathrm{RH}\right.$, and a $16-\mathrm{h}$ photoperiod) into double-walled delicate nylon-mesh cages $(40 \times 34 \times 50 \mathrm{~cm})$. The beetle's colonies were feed on the wheat aphid, Schizaphis graminum (Hemiptera: Aphididae), and reared on wheat (Triticum aestivum) seedlings. For all experiments, C. undecimpunctata adults were famished for $24 \mathrm{~h}$ before beginning any investigation.

\section{Olfactometer bioassays}

Behavioral responses of C. undecimpunctata adults to volatiles from different sources were evaluated in a 4arm olfactometer (Model QT-WII01), a custom-made by Channel Tech Co., Ltd., Beijing, China, under the laboratory conditions described above. A 60-W lamp was provided during the entire bioassay. The olfactometer's four arms were connected to a pump that maintained continual pure air in the four arms and at meanwhile, vacuuming out by central suction the odors emitted by the treatments. The four airflow meters were connected by the four arms to ensure that the control and odorant airstreams are equal in each arm. Both sexes were used in separate experiments to test the effect of different odor sources. An individual ladybeetle adult (virgin male or virgin female or mated male or mated female) was placed on the surface of the central arena. Each odor source was placed randomly in one of the three chambers (three active chambers), and the 4th chamber was empty (inactive chamber). The odor sources evaluated were: un-infested bean seedling, 20 individuals of $A$. craccivora alone, combination 'infested bean seedling + 20 individuals of aphids.' Each adult was used only once. After 10 observations, the total number of individual visits in the arms was represented as one replicate. Eight replicates were used for each experiment.

\section{Statistical analysis}

The data from olfactometer experiments were statistically evaluated by analyzing variance two-way ANOVA, followed by Fisher's LSD test. The significance level was set to 0.05 .

\section{Results}

In the experiments of the present study, individuals of $C$. undecimpunctata responded to the olfactometer's different odor sources with partly evident differences. The two-way analysis of variance provided information regarding the interaction between predator type and attraction types. The analysis indicated a significant difference in attraction types $(F=79.63 ; \mathrm{df}=3 ; P<$ $.001)$, and interaction between predator types and attraction types $(F=4.71$; df $=9 ; P<.001)$, while difference among predator types was non-significant $(F=0.13$; df $=$ 3; $P=0.13)$.

Olfactory bioassay on different predator types (virgin and mated males and females) of C. undecimpunctata adults searching behavior showed that the odor of "infested bean plant + aphids" was significantly more attractive $(P<0.001)$ to the ladybird beetle than the other odors from attraction types "un-infested bean plant or aphids" (Table 1). Differences between males and females of $C$. undecimpunctata in the olfactory response to "infested bean plant + aphids" odor were very remarkable. The percentage of the positive reaction from mated females to the odor source "infested bean plant + aphids" was significant higher $(F=3.62$; df $=3,7 ; P=$ $0.03)$ than the percentage of response of tested virgin and mated males. Virgin males and females were response a stronger to volatiles emitted from un-infested bean plant $(F=9.47$; $\mathrm{df}=3,7 ; P<0.001)$ than mated males and females (Table 1). Non-significant difference was found among the tested virgin and mated males and females to the chamber without an odor source $(F=$ 1.00 ; $\mathrm{df}=3,7 ; P=0.41)$. The statistical analysis of attraction types revealed that volatiles emitted from "infested bean plant + aphids" had a significant influence on all predator's types compared with other attraction types $(P$ $<0.001)$.

Means followed by the same capital letter per row and the same small letter per column do not differ by the Fisher LSD test at 5\% probability.

There was a clear tendency between both sexes, but non-significant difference was observed between the percentage of virgin and mated males (Fig. 1) in response to the odor sources "infested bean plant + aphids" ( $F=$ 0.05 ; $\mathrm{df}=1,7 ; P=0.83)$. The highest percentage of positive response in the case of mated males was obtained by the odor emitted by aphids $(F=14.91$; df $=1,7 ; P=$ $0.006)$ and by un-infested bean plant $(F=58.33$; $\mathrm{df}=1$, 7; $P=<0.001)$ compared with virgin males.

In the case of virgin and mated females (Fig. 2), no evident tendencies were observed in response "aphids," and so the percentage responding between the odor source 
Table 1 Percentage of response \pm SE of virgin and mated male and female of Coccinella undecimpunctata to different odor sources, tested in a 4-arm olfactometer (single individual experiment)

\begin{tabular}{|c|c|c|c|c|c|c|c|}
\hline \multirow{2}{*}{$\begin{array}{l}\text { Predator } \\
\text { type }\end{array}$} & \multirow[t]{2}{*}{ No. } & \multirow{2}{*}{$\begin{array}{l}\text { No. of } \\
\text { non- } \\
\text { response }\end{array}$} & \multicolumn{4}{|l|}{$\%$ Response } & \multirow[b]{2}{*}{$P$ value } \\
\hline & & & Un-infested bean plant & Aphids & Infested bean plant with aphids & Empty chamber & \\
\hline Virgin male & 80 & 15 & $25.00 \pm 1.89 \mathrm{a}(\mathrm{AB})$ & $21.25 \pm 3.50 \mathrm{~b}(\mathrm{~B})$ & $31.25 \pm 2.26 \mathrm{~b}(\mathrm{~A})$ & $3.75 \pm 1.83$ a $(C)$ & $<0.001$ \\
\hline Virgin female & 80 & 16 & $21.25 \pm 1.25$ a (B) & $17.50 \pm 2.50 \mathrm{~b}(\mathrm{~B})$ & $36.25 \pm 4.20 \mathrm{ab}(\mathrm{A})$ & $5.00 \pm 1.89$ a (C) & $<0.001$ \\
\hline Mated male & 80 & 14 & $12.50 \pm 2.50 \mathrm{~b}(\mathrm{~B})$ & $30.00 \pm 2.67$ a (A) & $32.50 \pm 5.90 b(A)$ & $7.50 \pm 2.50 \mathrm{a}(\mathrm{B})$ & $<0.001$ \\
\hline Mated female & 80 & 12 & $13.75 \pm 1.83 \mathrm{~b}(\mathrm{~B})$ & $20.00 \pm 2.67 b(B)$ & $47.50 \pm 3.13$ a (A) & $3.75 \pm 1.82$ a (C) & $<0.001$ \\
\hline$P$ value & & & $<0.001$ & 0.014 & 0.03 & 0.41 & \\
\hline L.S.D (A) & & 4.12 & & & & & \\
\hline L.S.D (B) & & 4.12 & & & & & \\
\hline L.S.D $(A * B)$ & & 8.25 & & & & & \\
\hline
\end{tabular}

"aphids" were non-significant different $(F=0.47 ; \mathrm{df}=1$, 7; $P=0.52$ ). In fact, more percentage of mated ladybeetle females responded to the odor source "infested bean plant + aphids" ( $F=14.54 ; \mathrm{df}=1,7 ; P=0.007)$ compared with virgin female. On the other hand, the virgin ladybeetle females showed significant difference in attraction by the odor source "un-infested bean plant" $(F=21.00$; $\mathrm{df}=1,7 ; P=0.003)$. However, these experiments also showed clearly that the combination of infested bean plant with aphids was the most attractive odor source for adults of $C$. undecimpunctata tested in the olfactometer.

\section{Discussion}

In response to herbivore damage, numerous plants produce a specific blend of volatile chemicals, which can interfere with the foraging behavior of adult predators of herbivores (Dicke et al. 2003), including ladybeetle foraging behavior (Pettersson et al. 2008). In the experiments with $C$. undecimpunctata, results showed that most of the positive responses appeared with odor source from "infested bean plant + aphids," while an odor source from un-infested bean plant or aphids alone had a lower response percentage (Table 1). Several investigators supported the results. Bahlai et al. (2008) found that volatiles related to damage caused by prey feeding on an insect host and prey waste products may play a widely important role in prey-finding than volatiles associated with prey items alone. Ninkovic et al. (2001) showed that infested barley plants with Rhopalosiphum padi L. (Hemiptera: Aphididae) aphids significantly attracted more C.septempunctata adults than

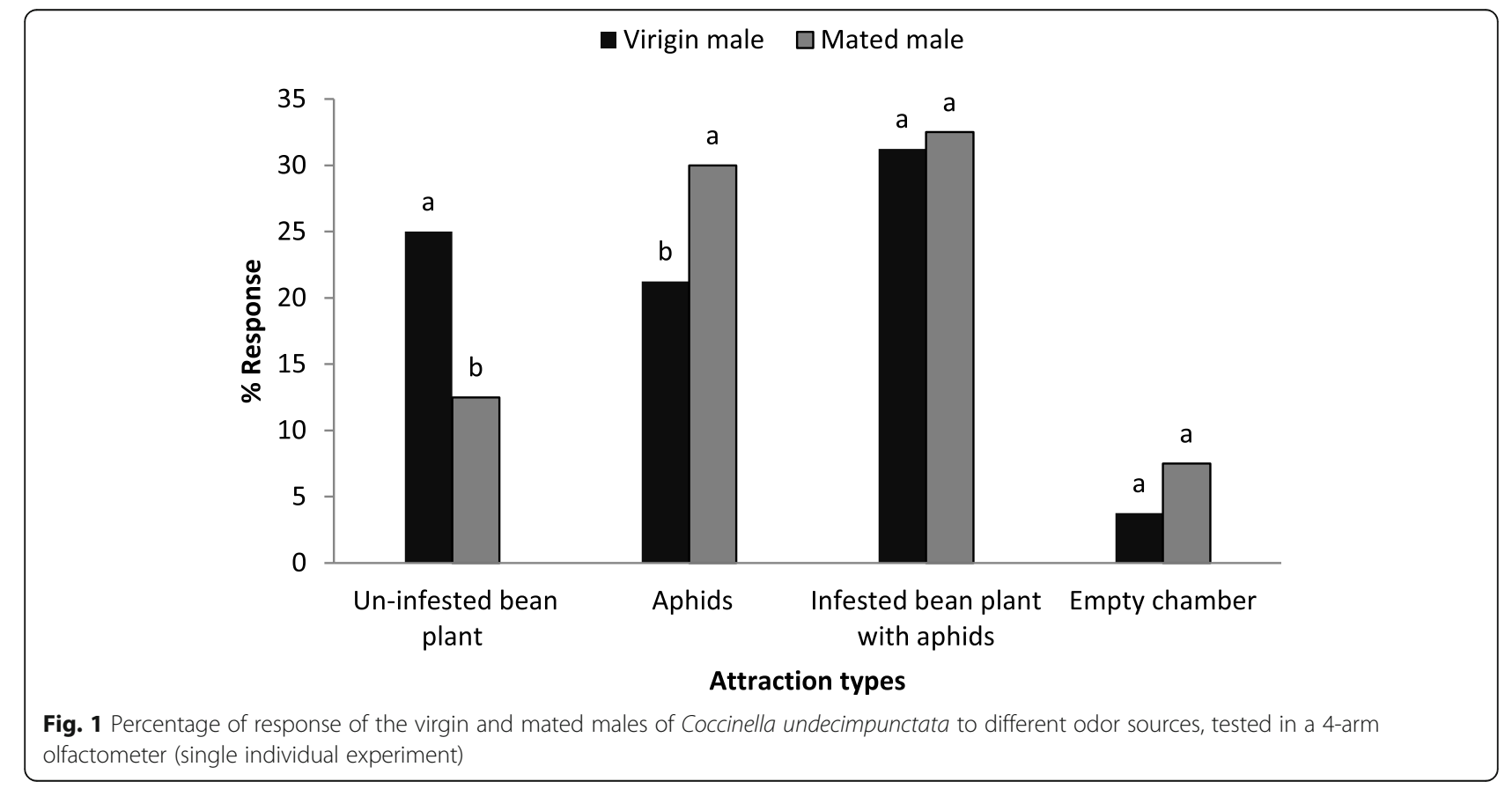




\section{- Virigin female $\square$ Mated female}

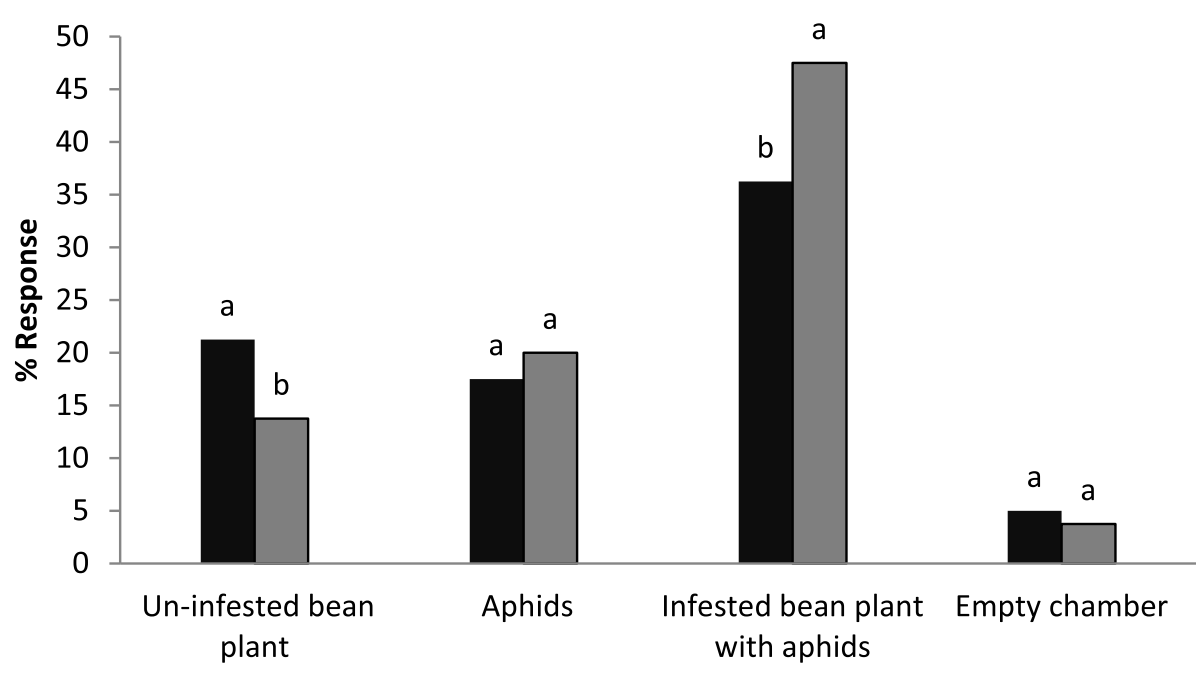

Attraction types

Fig. 2 Percentage of response of the virgin and mated females of Coccinella undecimpunctata to different odor sources, tested in a 4-arm olfactometer (single individual experiment)

healthy plants or undisturbed aphids alone. Norkute et al. (2020) also found that the C. septempunctata adults were significantly more attracted to volatile emitted from aphid-infested barley plants than un-infested plants, and the females were more prone than males to utilize olfactory cues when searching for their prey. The adult of Asian lady beetle Harmonia axyridis Pallas (Coleoptera: Coccinellidae) preferred aphid-infested plants over un-infested plants or aphids alone (Xiu et al. 2019). In a Y-tube olfactometer assay, the male and female of $H$. axyridis were showed attracting to Sophora japonica flowers to a similar extent (Chun-li et al. 2018). The Y-tube olfactometer bioassays revealed that $H$. axyridis and Oenopia conglobata (Coleoptera: Coccinellidae) species used of information from a plant-prey (Vicia faba-Aphis fabae) system, but $H$. axyridis exhibited a more complete response (Rondoni et al. 2017). Experienced Propylaea japonica (Thunberg) (Coleoptera: Coccinellidae) beetles were more attracted toward cues associated with aphid-infested plants compared with naive beetles (Wang et al. 2015). Adults of Cycloneda sanguinea L. (Coleoptera: Coccinellidae) were most attracted to the odors from infested tomato leaves + healthy aphids, Myzus persicae Sulzer (Hemiptera: Aphididae) than odor sources from healthy aphids or un-infested tomato leaves or infested tomato leaves + stressed aphids or stressed aphids (Heit et al. 2008). The present study showed that mated females of $C$. undecimpunctata had significantly higher than virgin females in response to the odor source "infested bean plant + aphids" (Fig. 2). This response might be due to females being more attracted than males to odor sources the need to provide a high quality food for egg production (Norkute et al. 2020). Ladybeetle adult usually orients its movement towards prey using olfactory cues. As shown in Table 1, non-significant difference was observed in the response between individuals of virgin male and female, and between mated male and female to un-infested bean plant. This response is possible because the host's secondary metabolism could have induced the volatiles after aphid attacks to attract both sexes of natural enemies as a defense (Francis et al. 2004). The most electrophysiologically active compounds of volatile released from $V . f a b a$ and attract different species of aphids were identified as (Z)-3-hexen-1-ol, 1-hexanol, (E)-2hexenal, (R)-(-)-linalool, (E)-caryophyllene, and (E)- $\beta$ farnesene (Webster et al. 2008).The semiochemicals associated with different species of aphids were identified. $\alpha$-pinene, $\beta$-pinene, Z,E-nepetalactone and $(-)-\beta$-caryophyllene, and (E)- $\beta$-farnesene were the most compounds found (Leroy et al. 2012). These compounds were potential attractants for $H$. axyridis adults (Leroy et al. 2012; Gencer et al. 2019).

\section{Conclusions}

The results of this study suggest that $C$. undecimpunctata searching behavior is based on the use of different sets of volatile compounds from many sources that might act as reliable indicators for the presence of its prey. Further investigations are needed to identify the volatile compounds emitted from the infested bean plant 
and aphid, which attract the C. undecimpunctata adults. Additionally, to evaluate the regulatory effects on the ladybeetles by these compounds, a new study that monitors the ladybeetle populations under field conditions when using the potential semiochemicals combinations should be conducted.

\section{Abbreviations}

${ }^{\circ} \mathrm{C}$ : Celsius; cm: Centimeter; h: hour; var.: Variety

\section{Acknowledgements}

Not applicable.

\section{Author's contributions}

I am the only author of this manuscript. So I am responsible for all the steps. The author read and approved the final manuscript.

\section{Funding}

Not applicable.

\section{Availability of data and materials}

Not applicable.

\section{Declarations}

Ethics approval and consent to participate

Not applicable.

\section{Consent for publication}

Not applicable.

\section{Competing interests}

The author declares that he has no competing interests.

Received: 21 December 2020 Accepted: 26 April 2021

Published online: 04 May 2021

\section{References}

Bahlai CA, Welsman JA, Macleod EC, Schaafsma AW, Hallett RH, Sears MK (2008) Role of visual and olfactory cues from agricultural hedgerows in the orientation behavior of multicolored asian lady beetle (Coleoptera: Coccinellidae). Environ Entomol 37(4):973-979. https://doi.org/10.1093/ee/3 7.4 .973

Chun-li X, Bin X, Hong-sheng P, Wei Z, Yi-zhong Y, Yan-hui LU (2018) Volatiles from Sophora japonica flowers attract Harmonia axyridis adults (Coleoptera: Coccinellidae). J Integrative Agri 17(0):60345-60347

Dedryver CA, Relac AL, Fabre F (2010) The conflicting relationships between aphids and men: A review of aphid damage and control strategies. C R Biologies 333(6-7):539-553. https://doi.org/10.1016/j.crvi.2010.03.009

Dicke M, van Poecke RMP, de Boer JG (2003) Inducible indirect defence of plants: From mechanisms to ecological functions. Basic appl Ecol 4(1):27-42. https:// doi.org/10.1078/1439-1791-00131

Francis E, Lognay G, Haubruge E (2004) Olfactory responses of the aphid and host plant volatile releases: (E)-p-farnesene an effective kairomone for the predator Adalia bipunctata. J Chem Ecol 30(4):741-755. https://doi.org/10.1 023/B:JOEC.0000028429.13413.a2

Gencer NS, Kumral NA, Altin I, Pehlevan B (2019) Response of aphid predators to synthetic herbivore induced plant volatiles in an apple orchard. Rev Colomb Entomol 45(2):e7953

Heit G, Cohen G, Mareggiani G (2008) Impact of odor signals on Cycloneda sanguine (Coleoptera: Coccinellidae) searching behavior. Cien Inv Agr 35(2): 205-210

Jabbar AS, Zawrah MFM, Amer SAM, Saleh AAA (2020) Ecological and Biological Studies of Certain Predatory Insects of Aphid Aphis craccivora (Koch.) On Cowpea. Res J Parasitol 15(1):20-30. https://doi.org/10.3923/jp.2020.20.30

Leroy PD, Schillings T, Farmakidis J, Heuskin S, Lognay G, Verheggen FJ, Brostaux $Y$, Haubruge E, Francis F (2012) Testing semiochemicals from aphid, plant and conspecific: attraction of Harmonia axyridis. Insect Sci 19(3):372-382. https://doi.org/10.1111/j.1744-7917.2011.01449.x
Ninkovic V, Al Abassi S, Petersson J (2001) The influence of aphid-induced plant volatiles on ladybirds Beetle searching behavior. Biol Cont 21(2):191-195. https://doi.org/10.1006/bcon.2001.0935

Norkute M, Olsson U, Ninkovic V (2020) Aphids-induced plant volatiles affect diel foraging behavior of a ladybird beetle Coccinella septempunctata. Insect Sci 27(6):1266-1275. https://doi.org/10.1111/1744-7917.12734

Pettersson J, Ninkovic V, Glinwood R, Abassi SA, Birkett M, Pickett J, Wadhams L (2008) Chemical stimuli supporting foraging behavior of Coccinella septempunctata L. (Coleoptera: Coccinellidae): volatiles and allelobiosis. Appl Ent Zool 43(3):315-321. https://doi.org/10.1303/aez.2008.315

Rondoni G, lelo F, Ricci C, Conti E (2017) Behavioural and physiological responses to prey-related cues reflect higher competitiveness of invasive vs. native ladybirds. Sci Rep 7:3716

Salman AMA, Abdel-Moniem ASH, Obiadallac AH (2007) Influence of Certain Agricultural Practices on the Black Legume Aphid, Aphis craccivora Koch, Infesting Broad Bean Crops and the Relation between the Infestation and Yield of Plants in Upper Egypt. Arch Phytopathol Plant Prot 40(6):395-405. https://doi.org/10.1080/03235400600627635

Wang P, Su J, Ouyang F, Ge F (2015) Orientation behavior of Propylaea japonica toward visual and olfactory cues from its prey-host plant combination. Entomol Experim Appl 155(2):162-166. https://doi.org/10.1111/eea.12295

Webster B, Bruce T, Dufour S, Birkemeyer C, Birkett M, Hardie J, Pickett J (2008) Identification of volatile compounds used in host location by the black bean aphid, Aphis fabae. J Chem Ecol 34(9):1153-1161. https://doi.org/10.1007/s1 0886-008-9510-7

Xiu C, Zhang W, Xu B, Wyckhuys KAG, Cai X, Su H, Lu Y (2019) Volatiles from aphid-infested plants attract adults of the multicolored Asian lady beetle Harmonia axyridis. Biol Cont 129:1-11. https://doi.org/10.1016/j.biocontrol.201 8.11 .008

\section{Publisher's Note}

Springer Nature remains neutral with regard to jurisdictional claims in published maps and institutional affiliations.

\section{Submit your manuscript to a SpringerOpen ${ }^{\circ}$ journal and benefit from:}

- Convenient online submission

- Rigorous peer review

- Open access: articles freely available online

High visibility within the field

- Retaining the copyright to your article

Submit your next manuscript at $\boldsymbol{\nabla}$ springeropen.com 